\title{
Are we Missing Barrett's Esophagus in Our Busy Endoscopy Practice? Improving Detection
}

\author{
Amit Kumar Dutta ${ }^{1}$ \\ ${ }^{1}$ Department of Gastrointestinal Sciences, Christian Medical College \\ and Hospital, Vellore, Tamil Nadu, India \\ J Digest Endosc 2022;13:36-43.
}

Address for correspondence Amit Kumar Dutta, MD, DM, Department of Gastrointestinal Sciences, Christian Medical College and Hospital, Vellore 632004, Tamil Nadu, India (e-mail: akdutta1995@gmail.com).

\begin{abstract}
Keywords

- Barrett's esophagus

- dysplasia

- image enhanced endoscopy

- risk factors

Barrett's esophagus (BE) denotes the replacement of stratified squamous epithelium of esophagus by columnar epithelium. It is associated with a significantly increased risk of esophageal adenocarcinoma and hence patients with BE are advised endoscopic surveillance for early detection of dysplastic and neoplastic lesions. Esophageal cancer is the sixth most common cancer in terms of incidence and mortality in India. Around 15 to $25 \%$ of esophageal cancers are adenocarcinoma. BE is likely to be an important precursor of esophageal adenocarcinoma and we may be missing patients with $\mathrm{BE}$ in our busy endoscopy practice. The detection of $\mathrm{BE}$ may be improved by identifying highrisk groups, performing thorough endoscopic examination, and applying newer imaging techniques. The high-risk group includes patients with chronic gastroesophageal reflux disease, obesity, smoking, etc. During endoscopic examination, a careful assessment of the gastroesophageal junction and identification of important landmarks such as gastroesophageal junction and $Z$ line are essential to detect BE. Management of $\mathrm{BE}$ depends on the detection of dysplasia and for this four quadrant mucosal biopsy is recommended every 1 to $2 \mathrm{~cm}$. However, random biopsy samples only a small area of mucosa and advanced technologies for real-time detection of dysplasia and neoplasia may overcome this limitation. In this review, we discuss the current scenario of BE in India and ways to improve the detection of BE including dysplastic lesions.
\end{abstract}

\section{Introduction}

The esophageal mucosa is lined by stratified squamous epithelium. Barrett's esophagus (BE) is characterized by the replacement of the stratified squamous epithelium by columnar epithelium. ${ }^{1}$ The columnar metaplasia may be intestinal or gastric type. In countries such as the USA, BE is diagnosed only in the presence of intestinal metaplasia (IM). ${ }^{2}$ However, gastric metaplasia is also associated with neoplastic progression and in countries such as the UK, both gastric and intestinal columnar metaplasia are considered as BE. ${ }^{2}$ The Indian Society of Gastroenterology Task Force on gastroesophageal reflux disease (GERD) has also endorsed the presence of gastric or intestinal metaplasia on histopathology as diagnostic of $\mathrm{BE}^{3}$ The key factor predisposing to the development of BE is GERD. As $\mathrm{BE}$ may progress to dysplasia and adenocarcinoma in some patients, periodic surveillance is recommended to detect lesions at an early stage.
DOI https://doi.org/ 10.1055/s-0041-1741465. ISSN 0976-5042. (c) 2022. Society of Gastrointestinal Endoscopy of India. All rights reserved.

This is an open access article published by Thieme under the terms of the Creative Commons Attribution-NonDerivative-NonCommercial-License, permitting copying and reproduction so long as the original work is given appropriate credit. Contents may not be used for commercial purposes, or adapted, remixed, transformed or built upon. (https://creativecommons.org/ licenses/by-nc-nd/4.0/)

Thieme Medical and Scientific Publishers Pvt. Ltd., A-12, 2nd Floor, Sector 2, Noida-201301 UP, India 
Table 1 Frequency of Barrett's esophagus in Indian patients

\begin{tabular}{|c|c|c|c|c|}
\hline Study & $\begin{array}{l}\text { Number of } \\
\text { patients }\end{array}$ & Inclusion criteria & Columnar metaplasia & $\begin{array}{l}\text { Specialized intestinal } \\
\text { metaplasia }\end{array}$ \\
\hline $\begin{array}{l}\text { Amrapurkar et al, } 1998 \\
\text { Mumbai }\end{array}$ & 150 & Dyspepsia & $4.7 \%$ & $2.6 \%$ \\
\hline $\begin{array}{l}\text { Dhawan et al, } 2001 \\
\text { Mumbai }\end{array}$ & 271 & $\begin{array}{l}\text { Patients undergoing upper } \\
\text { gastrointestinal endoscopy }\end{array}$ & & $6 \%$ \\
\hline $\begin{array}{l}\text { Punia et al, 2006, } \\
\text { Chandigarh }\end{array}$ & 55 & GERD & $23.6 \%$ & $10.9 \%$ \\
\hline $\begin{array}{l}\text { Mathew et al, } 2011 \\
\text { Mumbai }\end{array}$ & 278 & GERD & $16.54 \%$ & $8.99 \%$ \\
\hline $\begin{array}{l}\text { Wani et al, } 2014 \\
\text { Srinagar }\end{array}$ & 378 & GERD & $14.8 \%$ & $2.38 \%$ \\
\hline
\end{tabular}

$\mathrm{BE}$ is associated with 30 to 40 times increased the risk of esophageal adenocarcinoma. ${ }^{4}$ Esophageal cancer is the sixth most common cancer in India and 15 to $25 \%$ of them are adenocarcinoma. ${ }^{5}$ The majority of them are locally advanced at the time of diagnosis. ${ }^{5}$ Considering the high prevalence of GERD, BE is likely to be an important precursor of esophageal adenocarcinoma among the Indian patients and we may be missing patients with BE in our busy endoscopy practice. There is a need for increased awareness and careful examination during endoscopy to improve the detection of $\mathrm{BE}$.

\section{Barrett's Esophagus in Indian Population}

Globally, the prevalence of BE is estimated to be between 0.6 and $1.1 \%{ }^{6,7}$ About 2 to $5 \%$ of patients undergoing upper gastrointestinal (UGI) endoscopy have BE and this figure increases to 5 to $15 \%$ in those with GERD. ${ }^{6}$ The prevalence is higher in western countries. ${ }^{6}$ The annual rate of development of adenocarcinoma in BE is $\sim 0.1$ to $0.5 \%{ }^{7,8}$ The risk is higher in patients with dysplasia, especially high-grade dysplasia (HGD) and long segment BE. ${ }^{8}$

$\mathrm{BE}$ is considered to be uncommon in the Asian region. However, a meta-analysis of 51 studies from the Asian countries estimated the pooled prevalence of endoscopic BE to be $7.8 \%$ (95\% CI: 5-12.1\%) and biopsy confirmed BE to be $1.3 \%$ (95\% CI: $0.7-2.2 \%$ ). The frequency of low-grade dysplasia (LGD) was 6.9\%. Importantly, HGD was noted in 3\% and esophageal adenocarcinoma (EAC) in $2 \%$. The authors also noted a rising trend of $\mathrm{BE}$ in the last three decades. India had one of the highest frequencies of $\mathrm{BE}$ among the Asian countries. This has also been noted from a study on multiethnic population from Malaysia where the people of Indian origin were more frequently affected than the Malay and Chinese ethnic groups. ${ }^{9}$ Based on these observations, it is noted that BE is not uncommon among the Indian population, and the frequency of HGD and EAC among them is similar to that observed in the west.

Studies assessing the frequency of BE in India have shown a wide range from $2.6 \%$ to $23.6 \%{ }^{10-13}$ This may be due to differences in the definition of $\mathrm{BE}$, target population, and study design. - Table 1 summarizes the observations from the Indian studies. ${ }^{10-13}$ Patients with BE were usually in the 5 th to 6 th decades of life and men were affected two to four times more commonly than women. The frequency was noted to be higher in patients with GERD compared with unselected patients undergoing endoscopy or in patients with dyspepsia. In one of the studies, the presence of columnar metaplasia (gastric or intestinal) was noted in $16.54 \%$ of cases, while IM was noted in $8.99 \%$ of patients with GERD. ${ }^{10}$ In the same study, the median circumferential extent was $2 \mathrm{~cm}(1-10)$ and the median maximal extent was $3 \mathrm{~cm}(2-11)$. HGD/EAC and LGD were each noted in $\sim 1 \%$ of subjects. As noted in other regions of the world, shortsegment $B E$ (extent up to $3 \mathrm{~cm}$ ) is observed 6 to 8 times more frequently among the Indian patients than long-segment BE. ${ }^{13}$

\section{Improving Detection of Barrett's Esophagus}

Considering the increasing frequency of BE observed in Indian studies, there is a need to improve awareness and detection. This includes the identification of high-risk individuals and endoscopic detection of $\mathrm{BE}$. In addition, the management and outcome of BE depends on the identification of dysplasia. Several tools are available to improve the detection of dysplasia and their appropriate use may provide further benefit to the patients.

I) Identifying high-risk group: Multiple risk factors have been identified for BE (-Fig. 1). Among them, GERD is most important. Other risk factors include large hiatus hernia, obesity, older age, male gender, smoking, and family history of BE.

a. Gastroesophageal Reflux Disease: The key factor in the development of BE is the reflux of acidic content from the stomach to the esophagus. Symptoms of GERD such as heartburn and regurgitation are present in $\sim 55$ to $60 \%$ of patients with $\mathrm{BE}$. The prevalence of $\mathrm{BE}$ in GERD varies from 5 to $15 \%$ and this rises further in the presence of other risk factors. ${ }^{14}$ The risk of BE increases 


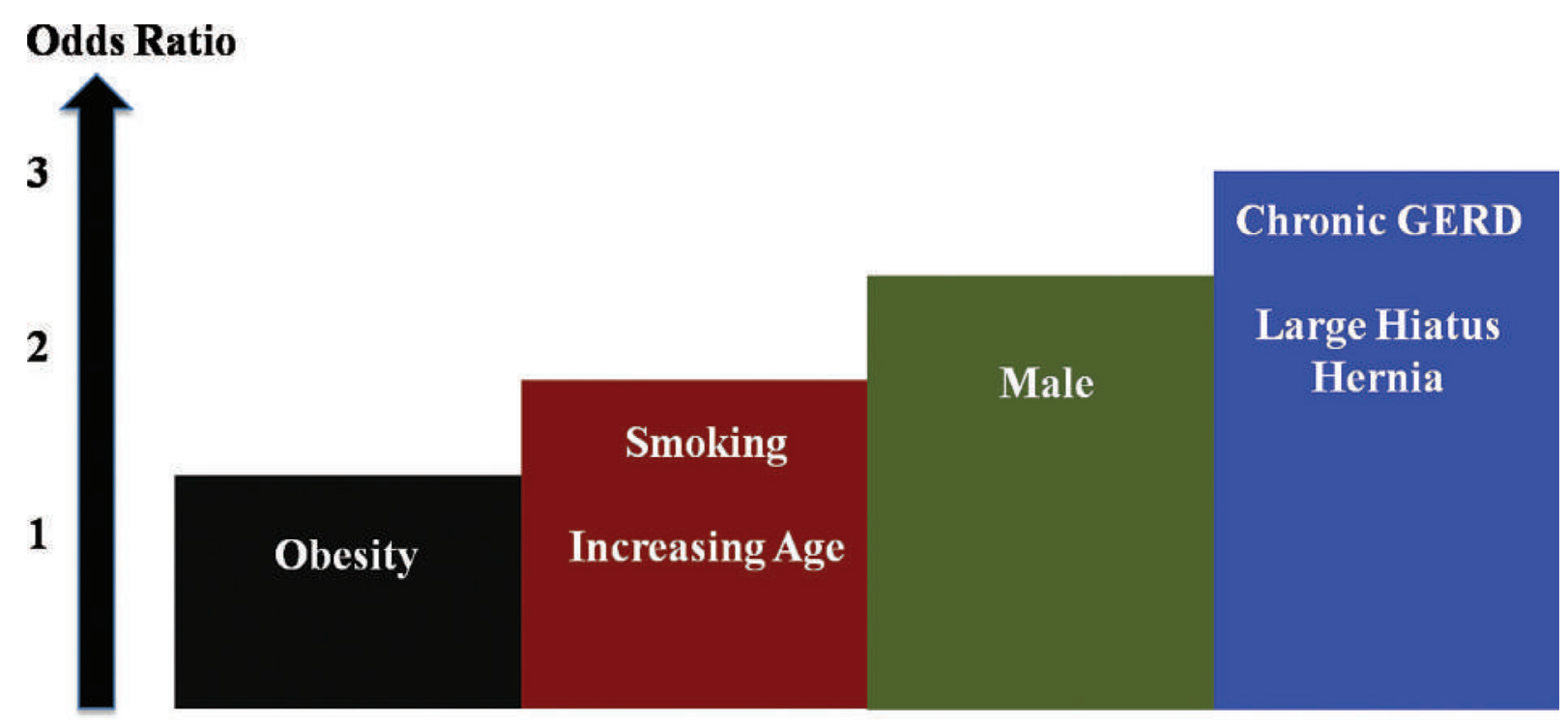

Fig. 1 Risk factors for development of Barrett's esophagus.

with the duration of GERD, especially after 5 years from the onset of symptoms. There are multiple studies from India, both community and hospital based, which have assessed the prevalence of GERD. A large communitybased study from Vellore, evaluated 6,174 participants and the frequency of GERD was found to be $8.7 \% .{ }^{15} \mathrm{~A}$ multicenter hospital-based study by the Indian Society of Gastroenterology Task Force on GERD found the prevalence to be $7.6 \%{ }^{16}$ Recently, a meta-analysis of studies on the prevalence of GERD in India estimated the pooled prevalence of this condition to be $15.6 \%$ $(11.1-20.1) .{ }^{17}$ These figures are not much lower than in the western countries. The significant burden of GERD in India and the high reported frequency of BE in GERD ( - Table 1) suggests that this is an important target group for the detection of $\mathrm{BE}$.

b) Other risk factors: $\mathrm{BE}$ is two to four times more common in men than women. ${ }^{18}$ Smoking almost doubles the risk of $\mathrm{BE}$ and obesity (abdominal or central obesity), the prevalence of which is rising in India, increases the risk to $\sim 1.5$ times. ${ }^{19,20}$ The presence of large hiatus hernia, older age ( $>50$ years), white race, and family history of BE or EAC are other risk factors. ${ }^{18,21}$ The cumulative risk of $\mathrm{BE}$ increases by $\sim 1.2 \%$ with each additional risk factor. ${ }^{6}$

Guidelines for screening for BE in high-risk group: Considering the higher risk of BE in patients with GERD and other risk factors, various societies have made recommendations for screening. The British Society of Gastroenterology recommends screening in individuals with chronic GERD and three or more other risk factors. ${ }^{22}$ The American College of Gastroenterology advises screening in patients with symptoms of GERD for more than 5 years and two or more additional risk factors. ${ }^{23}$ The ISG task force on GERD has recommended endoscopy in patients with longstanding symptoms of GERD. ${ }^{3}$ This would help assess the endoscopic severity of GERD, the presence of hiatus hernia, and BE. A population-based approach to identify the high-risk group may not be currently feasible in India due to the lack of community data on the prevalence of $\mathrm{BE}$ and the risk of progression to high-grade lesion as well as limitation of resources. However, opportunistic screening among patients visiting health care facilities with long standing reflux symptoms and other risk factors may be a suitable option.

Opportunistic detection of BE: Several endoscopies are performed regularly for various indications among which dyspepsia is perhaps the most common. This provides an excellent opportunity to look for features of $\mathrm{BE}$ in these patients as a subset of patients with BE may not have symptoms of GERD. These patients represent another target group for detection of $\mathrm{BE}$.

II) Endoscopic detection of Barrett's Esophagus: In addition to identifying the high-risk group, a systematic approach to endoscopic examination is essential for detecting $\mathrm{BE}^{24}$ This includes spending adequate time in inspecting gastroesophageal junction (GE) region, identifying landmarks, and recognizing $\mathrm{BE}$ and assessing presence of associated lesions. ${ }^{25}$ An improper endoscopic assessment without spending adequate time in the examination may be one of the key factors responsible for missing BE in a busy endoscopy practice.

a) Detecting BE: The endoscopic examination begins with cleaning the mucosal surface of mucus/debris. If the patient is restless or retching, sedation may be used. On endoscopy, BE appears as a salmon or pink colored mucosa. $\mathrm{BE}$ is defined as a distance of more than $1 \mathrm{~cm}$ between GE junction and $Z$ line (-Fig. 2). GE junction is located at the top of gastric mucosal folds. Excessive air insufflation should be avoided as it may flatten the folds. An alternative method to locate the GE junction is by noting the distal limit of palisading vessels in the 


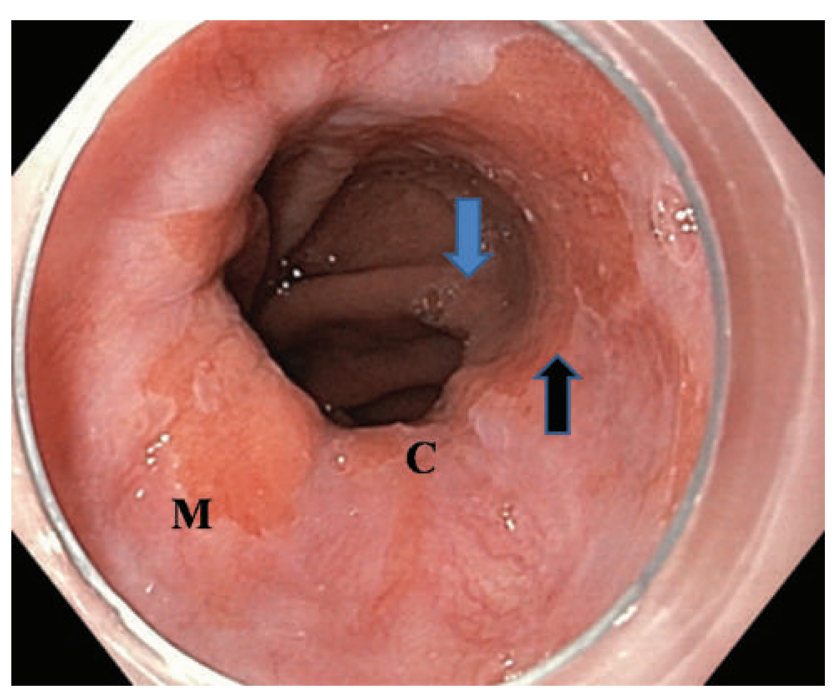

Fig. 2 Whit light image of the lower esophagus showing various landmarks to be examined for diagnosis and the estimation of extent of Barrett's esophagus. Blue arrow - gastroesophageal junction; Black arrow - Z line (squamocolumnar junction); C - circumferential extent of Barrett's esophagus; M - maximal extent of Barrett's esophagus.

esophagus. However the inter-observer variation is lesser for identifying gastric folds than palisading vessels. ${ }^{26}$ The $\mathrm{Z}$ line denotes the transition point between paleappearing stratified squamous epithelium of the esophagus to salmon/pink-colored columnar epithelium and is easily identified. If the distance between the GE junction and $\mathrm{Z}$ line is $>1 \mathrm{~cm}$, then $\mathrm{BE}$ is suspected and biopsy should be taken for histological confirmation of the diagnosis. The biopsy should be taken from four quadrants every $2 \mathrm{~cm}$ (Seattle protocol). ${ }^{1}$ The actual length of BE should be documented based on the Prague classification. This includes circumferential (C) and maximal (M) extent above the GE junction. ${ }^{27}$ The circumferential extent denotes the length up to which the entire mucosal circumference is involved. As BE frequently involves the esophagus in a non-uniform pattern with mucosal tongues, the maximal extent is assessed separately and denotes the maximum length of extension (in cases with mucosal tongues). The presence of mucosal islands should be noted separately. Based on the length of involvement, a long-segment $B E$ is defined as a maximal extent of $>3 \mathrm{~cm}$ and short segment as a maximal length of up to $3 \mathrm{~cm}$.

b) Identification of associated lesions: An adequate endoscopic examination includes assessment for other findings present along with $\mathrm{BE}$. The presence of hiatus hernia and its extent should be described. Erosive esophagitis and its severity should be documented. Significant esophagitis hampers histological assessment of $\mathrm{BE}$ and dysplasia, and such patients may need a repeat endoscopic assessment after 8 to 12 weeks of acid suppressant therapy. One should carefully look for the presence of nodules/elevated lesions and depressed lesions within Barrett's segment as it may be a focus of dysplasia or even adenocarcinoma. These areas should be biopsied, and sample sent in a separate container. A proper endoscopic assessment is crucial to detect $B E$ as well as avoid overdiagnosis. $A<1 \mathrm{~cm}$ segment of columnar metaplasia carries a very low risk of malignancy, and most societies recommend against biopsy and diagnosing BE in them to avoid unnecessary anxiety among patients. While endoscopy is the standard test to detect $\mathrm{BE}$, its invasive nature has led to the evaluation of less-invasive tools to detect BE. This includes devices (non-endoscopic) such as sponges and balloon to collect cells from the lower esophagus for assessing cytopathology and the presence of molecular markers of $\mathrm{BE} .^{1}$ The assessment of markers in blood (e.g., microRNA) and breath (e.g., volatile organic compounds) have also shown positive results. ${ }^{1}$ These tools are promising but are still in the stage of development. Currently, UGI endoscopy remains the standard test for detecting BE.

III) Improving detection of dysplasia in Barrett's Esophagus: In a small subgroup of patients, BE progresses to dysplasia and adenocarcinoma. The rate of progression to EAC increases from the group with "no dysplasia" (0.2$0.4 \%$ per year) to LGD (1-2\% per year) and HGD (4-8\% per year). ${ }^{1}$ The appropriate management of BE depends on the presence of dysplasia or EAC. ${ }^{28,29}$ Patients with HGD require endoscopic ablative therapy, while $\mathrm{EAC} /$ focal lesion may be managed with endoscopic removal or surgery. Patients with LGD need endoscopic surveillance every 6 to 12 months and more recently they are also being treated with ablative therapy. ${ }^{1}$ Patients with $\mathrm{BE}$ without dysplasia should be kept on endoscopic surveillance once every 3 to 5 years. Hence, dysplasia detection is the key to select appropriate therapy. An important limitation of the four-quadrant random biopsy (Seattle protocol) is that it samples a very small surface area of mucosa (3-4\% surface area) and may miss dysplasia if the dysplastic area is not sampled during biopsy. The compliance of endoscopists with the biopsy protocol may also be affected due to the time taken for biopsies and patient discomfort especially in those with long-segment BE. About $25 \%$ of EAC are detected in patients with BE who had a negative endoscopy (no dysplasia) in the past 1 year, highlighting the significant miss rate with conventional white light endoscopic examination and random biopsy. ${ }^{30}$ The use of advanced imaging techniques that can inspect the mucosa and identify dysplastic/neoplastic appearing mucosa in real time for targeted biopsy may overcome the limitation of random biopsy (-Table 2). ${ }^{28}$ Several such techniques are available that have been shown to be superior to conventional white light endoscopy in detecting dysplasia and reducing the number of biopsies required. ${ }^{8,31}$ Surveillance improves the detection of a highgrade lesion at an early stage when endoscopy or curative surgical treatment may be feasible ${ }^{32}$.

a) Digital chromoendoscopy: This technology uses digital manipulation of the wavelength of light to 
Table 2 Endoscopic techniques for real time detection of dysplasia in Barrett's esophagus

\begin{tabular}{|l|l|}
\hline Techniques & Examples \\
\hline Digital chromoendoscopy & $\begin{array}{l}\text { Narrow band imaging } \\
\text { Blue light imaging } \\
\text { i Scan }\end{array}$ \\
\hline Chemical spray & $\begin{array}{l}\text { Acetic acid } \\
\text { Methylene blue }\end{array}$ \\
\hline Endomicroscopy & $\begin{array}{l}\text { Confocal laser } \\
\text { endomicroscopy } \\
\text { Endocytoscopy }\end{array}$ \\
\hline Cross-sectional imaging & $\begin{array}{l}\text { Volumetric laser } \\
\text { endomicroscopy }\end{array}$ \\
\hline
\end{tabular}

highlight the surface characteristics of the mucosa (micro surface). In addition, they also highlight the vascular pattern, which is an advantage over dye-spray chromoendoscopy. They increase the detection rate of dysplasia in BE by $\sim 30 \% .^{33}$ Available technologies include narrow band imaging (NBI, Olympus), blue light imaging (BLI, Fujinon) and I-scan (Pentax). Among them, the largest number of research publications have been on the use of NBI in detecting dysplasia in BE. ${ }^{34}$ The surface pattern in BE may be of different types including ridge pattern, tubular pattern, villous pattern, cerebriform/gyrate pattern, or circular/oval pattern. ${ }^{35}$ The vessels may be in the honeycomb pattern, situated between mucosal ridges or appear as regularly branched structures. Hence, there is no single specific pattern for BE on digital chromoendoscopy. The main advantage lies in the detection of dysplasia/neoplasia in real time and taking targeted biopsy from the dysplastic/neoplastic area during endoscopy. - Fig. 3 shows the image of BE obtained by NBI and there is a regular pattern of microvessels and microsurface suggesting the absence of HGD. In this situation, the usual

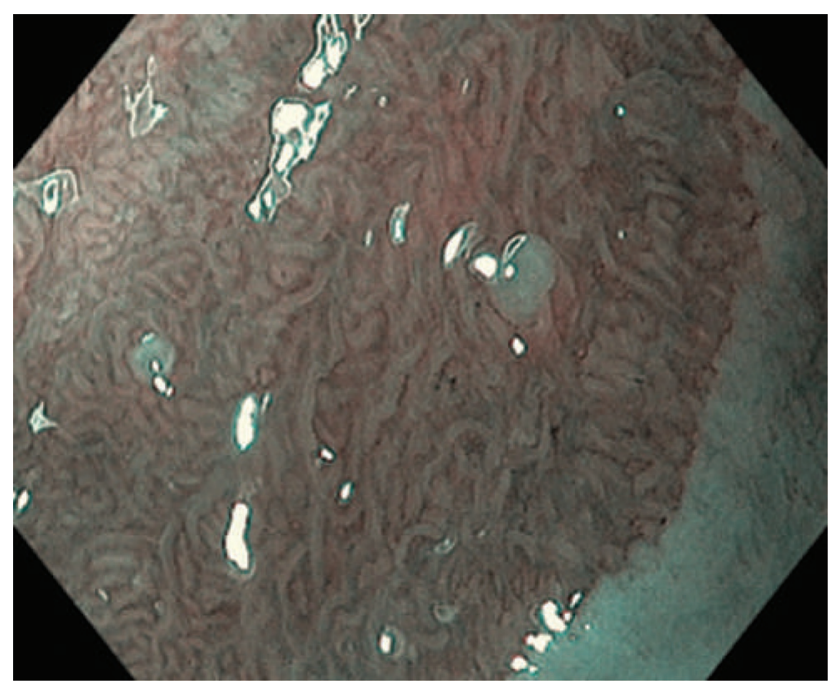

Fig. 3 Narrow band imaging of Barrett's esophagus showing regular microsurface and microvascular pattern. These features the suggest lack of high-grade dysplasia or neoplasia.

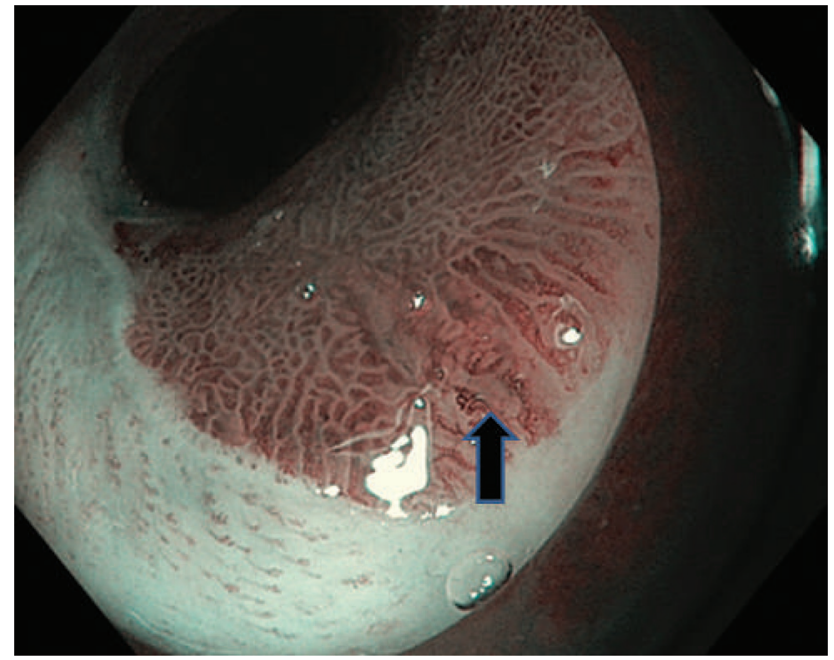

Fig. 4 Narrow band imaging of Barrett's esophagus showing a foca area with irregular microvascular pattern (arrow). This suggests the presence of high-grade dysplasia in this area.

random four quadrant biopsy is sufficient. However, in - Fig. 4, one area (arrow) shows irregular microvascular pattern suggestive of HGD and this area should be targeted for biopsy in addition to the four-quadrant biopsy.

The interpretation of images on NBI requires training but is not very difficult and a randomized study showed similar efficacy of classroom teaching versus self-directed learning. ${ }^{36}$ Several classification systems have been proposed to identify dysplasia on NBI or other techniques. ${ }^{37}$ The common theme across all these classifications is identifying irregularity in the surface and/or vascular pattern as a marker of dysplasia. The BING (Barrett's international NBI group) classification is one of the simple classifications for detecting dysplasia. ${ }^{38}$ The presence of a regular mucosal surface pattern (ridge villous, tubular or circular) and regular vascular pattern (vessels situated regularly along or between mucosal ridges) excludes dysplasia with an accuracy of $85 \%$. Irregularity of vascular and/or surface pattern suggests the presence of dysplasia. More recently, the Japanese experts have refined the BING classification (BING-J) to further elaborate the description of "flat pattern." ${ }^{39}$ This is described as a completely flat surface with no clear demarcation line and containing greenish thick vessels. This appearance is suggestive of non-dysplastic area. The performance of NBI in detecting HGD has been evaluated in a metaanalysis that showed a sensitivity of $96 \%$ and specificity of $94 \% .^{31}$

b) Dye-spray chromoendoscopy: This involves the spray of a dye on the mucosal surface to highlight the abnormal areas. ${ }^{40}$ Among these techniques, acetic acid spray chromoendoscopy has shown the best results in detecting dysplasia in $B E{ }^{41}$ Spray of dilute acetic acid (2.5\%) results in a change in the color of $\mathrm{BE}$ segment from salmon/pink to snow white 
(acetowhitening). Focal loss of acetowhitening is a strong predictor of dysplasia/neoplasia. In addition, surface characteristics such as irregularity, increased density, and absent pits have also been observed in advanced lesions. These features have been incorporated in a classification (PREDICT) and shown to have good performance in detecting HGD/EAC in Barrett's esophagus. $^{42}$ Acetic acid has the advantage of being cheap and can be easily procured. Another agent for dye-spray chromoendoscopy in BE is methylene blue. It is taken up by absorptive cells (intestine) but not gastric or esophageal epithelium. BE with intestinal metaplasia takes up the stain. In the presence of dysplasia or EAC, staining may be reduced and heterogeneous. This technique can help identify dysplastic areas in BE although a meta-analysis did not show this technique to be superior to random biopsy. ${ }^{43}$

c) Other techniques: Techniques such as confocal laser endomicroscopy and endocytoscopy provide highly magnified image of the epithelium and enable visualization of cellular and subcellular structures in real time (in vivo histology). ${ }^{44}$ They can identify columnar epithelial cells and goblet cells and nuclear abnormalities, suggestive of dysplasia or cancer. Another technique that has shown promising result in detecting dysplasia in BE is volumetric laser endomicroscopy. ${ }^{45}$ This provides a high-resolution cross-sectional image of mucosal microstructure, and a $6 \mathrm{~cm}$ area can be scanned within 90 seconds to a depth of $3 \mathrm{~mm}$. Molecular imaging to identify abnormally expressed genes by fluorescent probes is also being developed for the detection of dysplasia. ${ }^{46}$ While these technologies are promising, they are limited by the cost, interpretation of images, and availability.

An adjunctive technology to four quadrant random biopsy is the wide area trans-epithelial sampling (WATS-3D, CDx Diagnostics, NY). ${ }^{47}$ The surface of BE is scraped by a brush and cells are placed into a liquid medium. Atypical cells are identified by artificial intelligence-based system for further evaluation by pathol- ogist. This technique aims to cover a wider area of BE to reduce the sampling error. Along with the use of newer technologies, spending more time on examination has also shown to improve the detection of high-grade lesions. ${ }^{48}$ An important practical challenge in the application of newer technologies is the need for familiarity and training on the appearance of nondysplastic and dysplastic mucosa. This can be potentially overcome by the development of artificial intelligence systems to help with image interpretation. ${ }^{49}$ There has been a rapid pace of research in this area and the results so far are very promising. ${ }^{50,51}$

Practice Recommendations: For the primary detection of BE, a good WLE with four quadrant biopsies in patients with salmon/pink color mucosa extending for $>1 \mathrm{~cm}$ above GE may be sufficient. This holds true for both high-risk group as well as patients who are undergoing endoscopy for other indications. Hence, the availability of IEE should not impact detection of $B E$. Spending adequate time in the examination is crucial. The key benefit of IEE is in detecting dysplasia. In patients with a diagnosis of $\mathrm{BE}$, endoscopy for the detection of dysplasia should preferably include chromoendoscopy. In centers with IEE facilities (equipment and expertise), they should be used for real-time identification of dysplasia and targeted biopsy (-Table 3). In centers without IEE facilities, acetic acid spray is a suitable alternative as it is cheap and has shown good performance in detecting dysplasia in BE. The use of sedation may further facilitate proper examination by keeping the patient comfortable.

In conclusion, $\mathrm{BE}$ is not uncommon in Indian patients with GERD. The detection of BE may be improved by identifying the high-risk group and performing adequate and systematic examination during endoscopy. Among the tools for detection of dysplasia, imageenhanced endoscopy or acetic acid-based chromoendoscopy appear to be suitable options currently. The creation of multi-center national registry to collect data prospectively on patients with $\mathrm{BE}$ including

Table 3 Image-enhanced endoscopy to detect dysplasia in Barrett's mucosa: suggested steps

- Ensure patient comfort. Use sedation as required.

- Attach a cap (soft, transparent, or black) to the distal end of the endoscope.

- Clean the mucosal surface of mucus, debris, etc.

- Begin with a proper assessment of Barrett's mucosa with white light examination. Look for elevated or depressed areas, ulcers, etc.

- Switch to image-enhanced endoscopy. Assess the microsurface pattern in the area with Barrett's esophagus. Look for irregularity of microsurface pattern.

- Assess the microvascular pattern in the area with Barrett's esophagus. Look for irregularity of the microvascular pattern.

- After assessment of entire Barrett's mucosa with image-enhanced endoscopy including any abnormal areas seen on white light endoscopy, proceed to mucosal biopsy.

- If irregularity is noted on the microsurface pattern or microvascular pattern, then suspect dysplasia/neoplasia and take targeted biopsy from the site (only one to two bits to avoid fibrosis that may hamper future endoscopic resection/ dissection). In addition, four quadrant biopsy should be taken according to the Seattle protocol.

- If there are no irregularity of microsurface or microvascular pattern, proceed to four quadrant biopsy according to the Seattle protocol. 
follow-up will enable us to understand the magnitude of this condition, frequency of dysplasia, and the risk of progression to cancer. This would make the role of surveillance clearer among our patients and help formulate appropriate management guidelines.

\section{Funding}

None.

\section{Conflict of Interest}

None declared.

\section{References}

1 Peters Y, Al-Kaabi A, Shaheen NJ, et al. Barrett oesophagus. Nat Rev Dis Primers 2019;5(01):35

2 Marques de Sá I, Pereira AD, Sharma P, Dinis-Ribeiro M. Systematic review of the published guidelines on Barrett's esophagus: should we stress the consensus or the differences? Dis Esophagus 2020:doaa 115

3 Bhatia SJ, Makharia GK, Abraham P, et al. Indian consensus on gastroesophageal reflux disease in adults: a position statement of the Indian Society of Gastroenterology. Indian J Gastroenterol 2019;38(05):411-440

4 Cerrone SA, Trindade AJ. Advanced imaging in surveillance of Barrett's esophagus: is the juice worth the squeeze? World J Gastroenterol 2019;25(25):3108-3115

5 Krishnamurthy A, Behuria SS. Demographic trends in carcinoma esophagus from India along with a brief comparative review of global trends. South Asian J Cancer 2020;9(03):163-167

6 Qumseya BJ, Bukannan A, Gendy S, et al. Systematic review and meta-analysis of prevalence and risk factors for Barrett's esophagus. Gastrointest Endosc 2019;90(05):707-717.e1

7 Runge TM, Abrams JA, Shaheen NJ. Epidemiology of Barrett's esophagus and esophageal adenocarcinoma. Gastroenterol Clin North Am 2015;44(02):203-231

8 Maes S, Sharma P, Bisschops R. Review: surveillance of patients with Barrett oesophagus. Best Pract Res Clin Gastroenterol 2016; 30(06):901-912

9 Rajendra S, Kutty K, Karim N. Ethnic differences in the prevalence of endoscopic esophagitis and Barrett's esophagus: the long and short of it all. Dig Dis Sci 2004;49(02):237-242

10 Mathew P, Joshi AS, Shukla A, Bhatia SJ. Risk factors for Barrett's esophagus in Indian patients with gastroesophageal reflux disease. J Gastroenterol Hepatol 2011;26(07):1151-1156

11 Punia RS, Arya S, Mohan H, Duseja A, Bal A. Spectrum of clinicopathological changes in Barrett oesophagus. J Assoc Physicians India 2006;54:187-189

12 Amarapurkar AD, Vora IM, Dhawan PS. Barrett's esophagus. Indian J Pathol Microbiol 1998;41(04):431-435

13 Wani IR, Showkat HI, Bhargav DK, Samer M. Prevalence and risk factors for Barrett's esophagus in patients with GERD in Northern India; do methylene blue-directed biopsies improve detection of Barrett's esophagus compared the conventional method? Middle East J Dig Dis 2014;6(04):228-236

14 Eusebi LH, Cirota GG, Zagari RM, Ford AC. Global prevalence of Barrett's oesophagus and oesophageal cancer in individuals with gastro-oesophageal reflux: a systematic review and meta-analysis. Gut 2021;70(03):456-463

15 Chowdhury SD, George G, Ramakrishna K, et al. Prevalence and factors associated with gastroesophageal reflux disease in southern India: a community-based study. Indian J Gastroenterol 2019; 38(01):77-82

16 Bhatia SJ, Reddy DN, Ghoshal UC, et al. Epidemiology and symptom profile of gastroesophageal reflux in the Indian population: report of the Indian Society of Gastroenterology Task Force. Indian J Gastroenterol 2011;30(03):118-127

17 Rai S, Kulkarni A, Ghoshal UC. Prevalence and risk factors for gastroesophageal reflux disease in the Indian population: a metaanalysis and meta-regression study. Indian J Gastroenterol 2021; 40(02):209-219

18 Corley DA, Kubo A, Levin TR, et al. Race, ethnicity, sex and temporal differences in Barrett's oesophagus diagnosis: a large community-based study, 1994-2006. Gut 2009;58(02):182-188

19 Kamat P, Wen S, Morris J, Anandasabapathy S. Exploring the association between elevated body mass index and Barrett's esophagus: a systematic review and meta-analysis. Ann Thorac Surg 2009;87(02):655-662

20 Cook MB, Shaheen NJ, Anderson LA, et al. Cigarette smoking increases risk of Barrett's esophagus: an analysis of the Barrett's and Esophageal Adenocarcinoma Consortium. Gastroenterology 2012;142(04):744-753

21 Verbeek RE, Spittuler LF, Peute A, et al. Familial clustering of Barrett's esophagus and esophageal adenocarcinoma in a European cohort. Clin Gastroenterol Hepatol 2014;12(10):1656-63.e1

22 Fitzgerald RC, di Pietro M, Ragunath K, et al; British Society of Gastroenterology. British Society of Gastroenterology guidelines on the diagnosis and management of Barrett's oesophagus. Gut 2014;63(01):7-42

23 Shaheen NJ, Falk GW, Iyer PG, Gerson LBAmerican College of Gastroenterology. ACG clinical guideline: diagnosis and management of Barrett's esophagus. Am J Gastroenterol 2016;111(01): 30-50, quiz 51

24 Triggs JR, Falk GW. Best practices in surveillance for Barrett's esophagus. Gastrointest Endosc Clin N Am 2021;31(01): 59-75

25 Gorrepati VS, Sharma P. How should we report endoscopic results in patient's with Barrett's esophagus? Dig Dis Sci 2018;63(08): 2115-2121

26 Amano Y, Ishimura N, Furuta K, et al. Which landmark results in a more consistent diagnosis of Barrett's esophagus, the gastric folds or the palisade vessels? Gastrointest Endosc 2006;64(02): 206-211

27 Sharma P, Dent J, Armstrong D, et al. The development and validation of an endoscopic grading system for Barrett's esophagus: the Prague C \& M criteria. Gastroenterology 2006;131(05): 1392-1399

28 Gross SA, Kingsbery J, Jang J, Lee M, Khan A. Evaluation of dysplasia in Barrett esophagus. Gastroenterol Hepatol (N Y) 2018;14(04):233-239

29 Singh T, Sanghi V, Thota PN. Current management of Barrett esophagus and esophageal adenocarcinoma. Cleve Clin J Med 2019;86(11):724-732

30 Visrodia K, Singh S, Krishnamoorthi R, et al. Magnitude of missed esophageal adenocarcinoma after Barrett's esophagus diagnosis: a systematic review and meta-analysis. Gastroenterology 2016; 150(03):599-607.e7, quiz e14-e15

31 Mannath J, Subramanian V, Hawkey CJ, Ragunath K. Narrow band imaging for characterization of high grade dysplasia and specialized intestinal metaplasia in Barrett's esophagus: a meta-analysis. Endoscopy 2010;42(05):351-359

32 Corley DA, Levin TR, Habel LA, Weiss NS, Buffler PA. Surveillance and survival in Barrett's adenocarcinomas: a population-based study. Gastroenterology 2002;122(03):633-640

33 Qumseya BJ, Wang H, Badie N, et al. Advanced imaging technologies increase detection of dysplasia and neoplasia in patients with Barrett's esophagus: a meta-analysis and systematic review. Clin Gastroenterol Hepatol 2013;11(12):1562-70.e1, 2

34 Hajelssedig OE, Zorron Cheng Tao Pu L, Thompson JY, et al. Diagnostic accuracy of narrow-band imaging endoscopy with targeted biopsies compared with standard endoscopy with random biopsies in patients with Barrett's esophagus: a systematic 
review and meta-analysis. J Gastroenterol Hepatol 2021;36(10): 2659-2671

35 Sharma P, Brill J, Canto M, et al.White Paper AGA: Advanced Imaging in Barrett's Esophagus. Clinical gastroenterology and hepatology: the Official Clinical Practice Journal of the American Gastroenterological Association. 2015;13:2209-2218

36 Daly C, Vennalaganti P, Soudagar S, Hornung B, Sharma P, Gupta N. Randomized controlled trial of self-directed versus in-classroom teaching of narrow-band imaging for diagnosis of Barrett's esophagus-associated neoplasia. Gastrointest Endosc 2016;83(01): 101-106

37 Goda K, Fujisaki J, Ishihara R, et al. Newly developed magnifying endoscopic classification of the Japan Esophageal Society to identify superficial Barrett's esophagus-related neoplasms. Esophagus 2018;15:153-159

38 Sharma P, Bergman JJ, Goda K, et al. Development and validation of a classification system to identify high-grade dysplasia and esophageal adenocarcinoma in Barrett's esophagus using narrowband imaging. Gastroenterology 2016;150(03):591-598

39 Furuhashi H, Goda K, Shimizu Y, et al. Feasibility of a simplified narrow-band imaging classification system for Barrett's esophagus for novice endoscopists. J Gastroenterol 2019;54(07): 587-596

40 Singh R, Chiam KH, Leiria F, Pu LZCT, Choi KC, Militz M. Chromoendoscopy: role in modern endoscopic imaging. Transl Gastroenterol Hepatol 2020;5:39

41 Coletta M, Sami SS, Nachiappan A, Fraquelli M, Casazza G, Ragunath K. Acetic acid chromoendoscopy for the diagnosis of early neoplasia and specialized intestinal metaplasia in Barrett's esophagus: a meta-analysis. Gastrointest Endosc 2016;83(01): 57-67.e1

42 Kandiah K, Chedgy FJQ Subramaniam S, et al. International development and validation of a classification system for the identification of Barrett's neoplasia using acetic acid chromoendoscopy: the Portsmouth acetic acid classification (PREDICT). Gut 2018;67(12):2085-2091
43 Ngamruengphong S, Sharma VK, Das A. Diagnostic yield of methylene blue chromoendoscopy for detecting specialized intestinal metaplasia and dysplasia in Barrett's esophagus: a metaanalysis. Gastrointest Endosc 2009;69(06):1021-1028

44 Canto MI, Anandasabapathy S, Brugge W, et al; Confocal Endomicroscopy for Barrett's Esophagus or Confocal Endomicroscopy for Barrett's Esophagus (CEBE) Trial Group. In vivo endomicroscopy improves detection of Barrett's esophagus-related neoplasia: a multicenter international randomized controlled trial (with video). Gastrointest Endosc 2014;79(02):211-221

45 Trindade AJ, Smith MS, Pleskow DK. The new kid on the block for advanced imaging in Barrett's esophagus: a review of volumetric laser endomicroscopy. Therap Adv Gastroenterol 2016;9(03): 408-416

46 Sturm MB, Wang TD. Emerging optical methods for surveillance of Barrett's oesophagus. Gut 2015;64(11):1816-1823

47 Gross SA, Smith MS, Kaul VUS Collaborative WATS3D Study Group. Increased detection of Barrett's esophagus and esophageal dysplasia with adjunctive use of wide-area transepithelial sample with three-dimensional computer-assisted analysis (WATS). United European Gastroenterol J 2018;6(04):529-535

48 Gupta N, Gaddam S, Wani SB, Bansal A, Rastogi A, Sharma P. Longer inspection time is associated with increased detection of high-grade dysplasia and esophageal adenocarcinoma in Barrett's esophagus. Gastrointest Endosc 2012;76(03):531-538

49 Struyvenberg MR, de Groof AJ, van der Putten J, et al. A computerassisted algorithm for narrow-band imaging-based tissue characterization in Barrett's esophagus. Gastrointest Endosc 2021;93 (01):89-98

50 Lui TKL, Tsui VWM, Leung WK. Accuracy of artificial intelligenceassisted detection of upper GI lesions: a systematic review and meta-analysis. Gastrointest Endosc 2020;92(04):821-830.e9

51 Pannala R, Krishnan K, Melson J, et al. Artificial intelligence in gastrointestinal endoscopy. VideoGIE 2020;5(12):598-613 